Hsieh, Y., Apostolopoulos, Y. \& Sonmez, S. (May 2013): World at work: Hotel cleaners, Occupational and Environmental Medicine, 70(5), 360-364.

Made available courtesy of BMJ Publishing Group: http://oem.bmj.com/content/70/5/360

***Reprinted with permission. No further reproduction is authorized without written permission from BMJ Publishing Group. This version of the document is not the version of record. Figures and/or pictures may be missing from this format of the document. ***

\title{
World at work: Hotel cleaners
}

Yu-Chin (Jerrie) Hsieh, Ph.D. **

Department of Marketing, Entrepreneurship, Hospitality, and Tourism, Bryan School of Business and Economics, University of North Carolina Greensboro, 472 Bryan Building, 516 Stirling Street, Greensboro, NC 27402-6170, USA; y hsieh@uncg.edu; Tel (336) 334-4269, Fax (336) 334-5580

Yorghos Apostolopoulos, Ph.D.

Public Health Education, University of North Carolina Greensboro, Greensboro, USA

Emory University School of Medicine, Atlanta, USA

\section{Sevil Sönmez, Ph.D.}

Department of Marketing, Entrepreneurship, Hospitality, and Tourism, Bryan School of Business and Economics, University of North Carolina Greensboro, Greensboro, USA

** Corresponding author

Word Count: 2184 


\section{World at Work: Hotel Cleaners}

With tourism and hospitality representing the largest economic sector in the world ${ }^{1}$ and over 4.8 million rooms in accommodation establishments in the U.S. alone ${ }^{2}$, hotel cleaners comprise a significant occupational segment. Regardless of geographic variation, hotel cleaners are predominantly women, immigrants, and minorities working under adverse conditions such as long hours, ergonomic strain, chemical exposure, poor pay, low job control, job insecurity, and a wide array of other physical and mental health risks. ${ }^{3-5}$ Such exposure has produced disproportionately high health disparities among service occupations, including repetitive strain injury, musculoskeletal disorders, allergies, and psychological distress; hotel cleaners are both highly underserved and understudied as an occupational segment. ${ }^{6-8}$ In this paper, we will provide an overview of the plethora of work hazards encountered by hotel cleaners and propose effective measures to reduce these hazards in order to improve hotel cleaners' occupational safety and health.

\section{TASKS OF THE JOB}

Hotel cleaners perform cleaning tasks in lodging facilities, such as hotels, motels, and resorts. Various interchangeable terms have been used to identity these laborers, including "maids," "housekeepers," and "room attendants." important contribution to the core value of a hotel. Unlike cleaners in other private or commercial establishments, hotel cleaners are required to clean guest rooms to meet the quality standards of the individual hotel. They are also expected to exercise customer service skills when encountering hotel guests and to contribute to customers' overall satisfaction. ${ }^{10}$

The responsibilities of a hotel cleaner vary and generally include cleaning the guest rooms, hallways, and other public areas in the hotel. The specific tasks involved include changing sheets and towels; making beds; emptying wastebaskets; dusting and polishing furniture and equipment; scrubbing sinks, taps, toilets, and bathtubs; washing and mopping 
bathroom floors; vacuuming floors; replenishing supplies; pushing heavy supply carts; and responding to requests from guests and front desk employees.

The majority of hotel cleaners are women and immigrants with minimal education. ${ }^{3,11,12 .}$ The typical, full-time cleaner works one 8-hour shift per day, five days a week. Such a worker is usually expected to clean 12 to 16 rooms per shift, which allows for less than 30 minutes to

clean each room. ${ }^{3}$ A number of circumstances, including guests who request a late check-out or extremely dirty rooms that require deep cleaning, often delay the work process, forcing the cleaner to work longer hours or overtime. It is common practice among hotels to hire cleaners based on the fluctuations in room occupancy rates, resulting in part-time hours, variable hours, or seasonal work hours. ${ }^{12}$ Hotel cleaners under these circumstances often work for more than one hotel or hold a second job in addition to their hotel cleaner position in order to make ends meet. ${ }^{13}$ Even though the work of a hotel cleaner is important, hotel cleaners are considered to be among the lowest remunerated workers, and their pay cannot compare reasonably to that of other hotel positions. ${ }^{11,12,14}$ In general, their pay is slightly higher than minimum wage. In the UK, the average hourly pay for a hotel cleaner was between $£ 5.05$ and $£ 6.20^{14}$, and in the US, the median pay for hotel cleaners was $\$ 9.32$ per hour in 2011 (slightly above the federal minimum wage as set in 2009 at $\$ 7.25)$, or approximately $\$ 19,390$ per year. ${ }^{15}$

\section{HAZARDS OF THE JOB}

In addition to long work hours and low pay, hotel cleaners are exposed to serious occupational hazards in the course of performing their everyday cleaning tasks. In fact, according to a study of hotel records covering thousands of employee injuries, this position represents the highest overall injury rate among all categories of hotel employees, with an injury rate of $10.4 \%$, almost double the injury rate for non-housekeepers (5.6\%). ${ }^{6}$ Occupational hazards hotel cleaners are exposed to can include physical, chemical, biological, and psychosocial. Table 1 summarizes the work hazards faced by hotel cleaners. 


\section{Physical hazards}

Hotel housekeeping is physically demanding work, involving a series of repetitive movements (e.g., lifting, lowering, pushing, and rotating mattresses; pulling pillowcases off/onto pillows; carrying, folding, and tucking linen; stretching and bending; and pushing equipment and supply trolleys). A report from the Canadian Center for Occupational Safety and Health revealed that a hotel housekeeper changes his or her body position every three seconds while cleaning a room. ${ }^{5}$ If the average time spent cleaning each room is less than 25 minutes, a housekeeper would assume 8,000 different body postures during every eight-hour shift. ${ }^{5}$ High aerobic strain, heavy static muscular loads, awkward postures, overexertion, and the fast-paced work required to meet their daily room quotas are all factors that put hotel cleaners at high risk for physical injury. They are also more likely than other workers to suffer repetitive motion injuries (RMI). ${ }^{5}$ The physical hazards faced by hotel cleaners are intensified by the poor ergonomic design of cleaning equipment (e.g., heavy trolleys, vacuum cleaners). In the course of a cleaning shift, hotel cleaners must push fully-loaded cleaning carts between rooms and often between floors. The introduction of luxury rooms featuring oversized mattresses, opulent linens, and an increase in upgraded amenities has exacerbated such physical hazards. ${ }^{7}$ Not surprisingly, this occupational group has the highest rate of musculoskeletal disorders among all hotel employees, with 3.2 cases per 100 workers. ${ }^{6}$ Studies of hotel housekeepers have indicated that the majority of the reports of pain made by the cleaners are in regard to their shoulders, hands, and upper and lower back. ${ }^{7}$ In addition, cleaning tasks are frequently performed under intense time pressure, making cleaners more prone to trauma hazards, such as slipping on wet floors, falling in tubs, and tripping over cords, linens, and other obstructions. Therefore, over time, working as a hotel cleaner can result in debilitating injuries, chronic pain, and a host of disabilities. 


\section{Chemical hazards}

Hotel cleaners are regularly exposed to hazardous chemicals in the cleaning products used to clean sinks, bath-tubs, toilets, and mirrors, including ammonia and solvents that irritate the skin, eyes, nose, and throat and cause dermatitis. Exposure to the volatile organic compounds contained in cleaning products can cause respiratory diseases and increase possible carcinogenic risks. ${ }^{16}$ Certain solvent-based products can damage the kidneys and reproductive organs. ${ }^{16}$ In addition, some hotel cleaners suffer allergic reactions upon exposure to the latex gloves used during cleaning.

\section{Biological hazards}

Biological hazards are defined by the Occupational Safety and Health Administration (OSHA) as infectious agents presenting an increased risk of illness, injury, or even death to employees. ${ }^{17}$ While cleaning guest rooms, hotel cleaners can potentially come in contact with broken glassware, used hypodermic needles and other medical waste left by guests, contaminated waste, human excreta, and mold and microbial contaminants. These biological hazards put hotel cleaners at risk for contracting infectious diseases such as HIV and hepatitis, among many others. ${ }^{4} 18$

\section{Psychosocial hazards}

Psychosocial hazards such as stress, violence, and bullying can potentially affect hotel cleaners' health and well-being adversely ${ }^{12}$. Work-related stress occurs when job demands exceed the worker's ability. Hotel cleaners usually perform their tasks under adverse psychosocial work conditions, including monotonous and strenuous work, heavy workloads, time constraints causing them to race through tasks to meet their daily room quotas, and demanding guests. ${ }^{1819}$ These workers also suffer from a lack of control over work organization, lack of support from supervisors or co-workers, lack of respect and recognition from managers, fear of job loss, and 
lack of promotional prospects. ${ }^{41819}$ Due to the lower level of entry to the job, this profession also attracts immigrants and migrants, who are more vulnerable to discrimination than native-born or local workers. ${ }^{20}$ A study of immigrant workers in Spain found that immigrants' experiences of discrimination are associated with poor self-health, a higher prevalence of chronic diseases, and mental health problems. ${ }^{21}$ Continued exposure to these adverse work conditions and ongoing psychosocial stress can lead to mental and physical health problems. For example, research has shown that stress is associated with a variety of physical disorders, ranging from headaches and depression to symptoms mimicking those of a heart attack. ${ }^{22}$ While performing their jobs, cleaners move between public and private spaces of hotel guests and at times are subjected to violence and bullying (e.g., sexual harassment, verbal abuse, physical assault by guests and/or co-workers), thus jeopardizing their safety, health, well-being, and work performance. $^{18}$

Table 1 Work Hazards of Hotel Cleaning

\begin{tabular}{|c|c|}
\hline Type of Hazards & Examples of Hazards \\
\hline Physical hazards & $\begin{array}{ll}\text { - } & \text { Repetitive movement } \\
\text { - } & \text { Lack of ergonomic equipment } \\
\text { - } & \text { Luxury guestrooms (oversized mattresses, opulent } \\
& \text { linens) }\end{array}$ \\
\hline Chemical hazards & $\begin{array}{ll}- & \text { Cleaning products } \\
- & \text { Latex gloves }\end{array}$ \\
\hline Biological hazards & $\begin{array}{ll}\text { - } & \text { Broken glassware } \\
\text { - } & \text { Used hypodermic needles } \\
\text { - } & \text { Contaminated waste } \\
\text { - } & \text { Human excreta } \\
\text { - } & \text { Mold/microbial contaminants } \\
\end{array}$ \\
\hline $\begin{array}{l}\text { Psychosocial } \\
\text { hazards }\end{array}$ & $\begin{array}{l}\text { - } \text { Work stress } \\
\text { - } \quad \text { Low control of work } \\
\text { - Lack of supervisor or co-worker support } \\
\text { - } \quad \text { Lack of respect } \\
\text { - } \text { Lack of recognition } \\
\text { - } \text { Harassment /violence/bullying } \\
\text { - } \\
\text { Discrimination }\end{array}$ \\
\hline
\end{tabular}




\section{MEASURES TO PROTECT HOTEL CLEANERS}

Preventive actions to protect hotel cleaners are needed at several levels to counteract the multiple hazards that cleaners face on the job. At the legislative level, enforcement of occupational safety standards are needed to address the unique hazards that lead to high injury rates among hotel cleaners. These regulations and standards must be enforced to eliminate known and suspected safety and health hazards. It is also important to emphasize the role of labor unions in representing hotel cleaners in negotiations with employers regarding wages, work hours, workloads, and work conditions to safeguard their rights and welfare. At the organizational level, employers must conduct risk assessments to identify and control reasonable and foreseeable health and safety risks and adopt interventions to prevent workrelated injuries and illnesses. Information, instructions, and training regarding workplace hazards should be provided to employees to ensure a safe work environment. Work safety procedures displayed through posters and graphics with clear language that employees can comprehend should be available to employees. Written procedures regarding work-related accidents should be developed and made available to employees to follow in the event of

accidents. ${ }^{18}$ Hotels can partner with academia, OSHA, National Institute of Occupational Safety and Health (NIOSH), and other organizations to enable better understanding of disparities in injury rates among hotel cleaners, to design effective systems to track occupational injuries and illnesses in the hotel sector, to improve work environments, and to develop effective remedies. ${ }^{4}$ More specific preventive measures include the following:

(1) To prevent physical hazards, safety training programs to instruct cleaners on safe work practices, including bed-making, bathroom and guest room cleaning practices, and proper handling of linen carts should be available. Training in ergonomics can help cleaners develop ergonomic working techniques, improve work posture, and reduce their physical burden. ${ }^{23}$ For example, instead of spreading bed sheets by using a fluffing or throwing motion involving shoulders and arms, hotel cleaners should be instructed to lay sheets on the bed and unfold 
them. Ergonomic cleaning tools, such as motorized linen carts that are highly maneuverable and can eliminate the exertion involved in pushing linen carts over carpeted areas, should replace old-fashioned, manually propelled and poorly-designed carts. ${ }^{4}$ Studies have found that the poor design and arrangement of furniture fixtures forces cleaners to stretch or overexert their bodies, resulting in increased musculoskeletal loads. ${ }^{24} 25$ Thus, guestrooms should be designed to be easy to clean, and furniture can be rearranged to minimize lifting, stretching, and bending. Additionally, instead of using flat sheets, hotels can use fitted bottom sheets to minimize mattress lifts, thereby reducing awkward postures associated with lifting heavy mattresses. This would also eliminate the unnecessary manipulation of bed linens required to make "hospital corners." The fast pace of work contributes to housekeeping injuries and accidents; tasks performed under intense time pressure are more likely to cause harm than those performed at a more moderate pace. ${ }^{5} \mathrm{~A}$ slower tempo should be upheld to minimize accidents and injuries resulting from a faster pace of work. Although on the surface, this may appear to increase the cost of labor, in reality, minimizing injuries will save hotels money in workman's compensation and absenteeism costs. In addition to incorporating factors that can affect workload, employers should solicit input from housekeeping employees and determine the optimal pace and amount of work required while limiting exposure to hazards. Furthermore, employers must ensure that workers take regular breaks, a practice that has been proven effective in promoting safety. ${ }^{1826}$

(2) To prevent chemical hazards, employers should inform, train, and supervise employees in the use and handling of cleaning chemicals. Employees should be instructed not to mix different chemicals. All containers and spray bottles should be clearly and bilingually labeled, and protective equipment (e.g., rubber gloves, eye shields, and face masks) must be provided to reduce chemical risks. ${ }^{16} 27$

(3) To minimize biological hazards, employers should eliminate any work practice that may lead to biological exposure and establish standard procedures for hotel cleaners to follow 
in handling dangerous waste and avoiding infections. First-aid staff should be trained in infection control procedures to handle potential exposures and hotel cleaners should wear appropriate personal protective equipment, use proper strength solutions, and practice good personal hygiene. $^{4} 17$

(4) To address psychosocial hazards, prevention and intervention strategies must be developed and implemented to reduce hotel cleaners' work stress and protect them from workplace violence and bullying. Administrative controls, such as job rotation, job redesign, work flow improvement, teamwork, and stress management should be used to minimize psychosocial hazards. ${ }^{18}$ Supervisor and coworker support can also alleviate stress and enhance wellness. ${ }^{19} \mathrm{~A}$ no-tolerance policy regarding violence, bullying, and discrimination should be established and enforced. Anyone who violates this policy needs to be held accountable for his or her actions; disciplinary consequences should be included in the policy. Reporting systems that do not penalize the worker filing complaints and proper procedures and training should be provided to minimize or eliminate occupational violence and bullying. Individual assistance for dealing with workplace incidents must be made readily available to workers. ${ }^{28}$

According to the National Occupational Research Agenda (NORA), the incidence and severity of work-related injuries and illnesses among hotel cleaners need to be lowered by $20 \%$, and the accommodation subsector needs to eliminate health disparities for priority population workers (i.e., Latino hotel cleaners). ${ }^{4}$ The NORA Services Council intends to ensure progress and track accomplishments of the accommodation subsector through 2016 . For these priorities of strategic importance to be materialized, multilevel stakeholder partnerships are needed.

\section{CONCLUSIONS}

As a highly underserved occupational segment, hotel cleaners are exposed to a multitude of disproportionately high work-induced hazards resulting in adverse physical, ergonomic, chemical, biological, and psychosocial afflictions and conditions. Multilevel, multisectoral, and 
multistakeholder preventive interventions are needed in order to prevent and alleviate the workrelated hazards and strains faced by hotel cleaners.

\section{REFERENCES}

1 World Tourism Organization (WTO). UNWTO Tourism Highlights, 2011 edition. http://www.unwto.org/facts/menu.html (accessed 6 June 2012).

2 American Hotel and Lodging Association (AHLA). 2011 Lodging Industry Profile. http://www.ahla.com/content.aspx?id=32567 (accessed 6 June 2012).

3 Wial H, Rickert J. US hotels and their workers: Room for Improvement, 2002. http://www.hotel-online.com/News/PR2002_3rd/Aug02_HotelJobs.html(accessed 25 May 2012).

4 National Institute for Occupational Safety and Health (NIOSH). Services Sector: Occupational Safety and Health Needs for the Next Decade of NORA-Safety and Health among Hotel Cleaners. DHHS(NIOSH) Publication No:2011-194.

5 Canadian Center for Occupational Health and Safety (CCOHS).Occupations \& workplaces: Hotel housekeeping.

http://www.ccohs.ca/oshanswers/occup_workplace/hotel_housekeeping.html (accessed 25 May 2012).

6 Buchanan S, Vossenas P, Krause N, et al. Occupational injury disparities in the US hotel industry. Am J Ind Med 2010; 53:116-125.

7 Krause N, Scherzer T, Rugulies R. Physical workload, work intensification and prevalence of pain in low wage workers: Results from a participatory research project with hotel room cleaners in Las Vegas. Am J Ind Med 2005; 48: 326-337.

8 Lee PT, Krause N. The impact of a worker health study on working conditions. J Public Health Policy 2002; 23:268-285. 
9 Kasavana ML, Brooks RM. Managing front office operations 7th ed. Lansing, MI: American Hotel and Lodging Education Institute 2005.

10 Powell PH, Watson D. Service unseen: The hotel room attendant at work. Int J Hospitality Management 2006; 25: 297-312.

11 Gautie J. Low-wage work in the wealthy world. New York City: Russell Sage Foundation Publications 2010.

12 Knox A. Lost in translation: an analysis of temporary work agency employment in hotels. Work, Employment, and Society 2010; 24(3): 449-467.

13 Krause N., Lee PT, et al. Health and working conditions of hotel guest room attendants in Las Vegas, 2012. June 2002. http://www.lohp.org/docs/pubs/vegasrpt.pdf (accessed 20 October 2012).

14 Warhurst C., Lloyd C, et al. The national minimum wage, low pay and the UK hotel industry: The case of room attendants. Sociology 2008; 42(6): 1228-1236.

15 U.S. Bureau of Labor Statistics (USBLS). Occupational employment and wages, May 2011. http://www.bls.gov/oes/current/oes372012.htm (accessed 25 May 2012).

16 Stellman JM, ed. Chemical, industries and occupations. Encyclopaedia of Occupational Health and Safety. International Labor Organization,1998.

17 Occupational Safety and Health Administration (OSHA). Biological agents. http://www.osha.gov/SLTC/biologicalagents/index.html (accessed 6 June 2012).

18 WorkCover NSW. Occupational health and safety in hospitality 2003. http://www.workcover.nsw.gov.au/formspublications/publications/Documents/ohs_in_the_ho spitality_industry_4133.pdf (accessed 5 June 2012)

19 European Agency for Safety and Health at Work (EU-OSHA). Managing psychosocial risks with cleaning workers. http://osha.europa.eu/en/publications/e-facts/efact51(accessed 4 June 2012). 
20 Lundberg H, Karlsson JC. Under the clean surface: working as a hotel attendant. Work, Employment, and Society 2011; 25(1): 141-148.

21 Agudelo-Suárez A, Ronda-Pérez E, et al. The effect of perceived discrimination on the health of immigrant workers in Spain. BMC Public Health 2011; 11(1): 1-9.

22 Wamala ASP, Mittleman MA, Schenck-Gustafsson K, Orth-GoméraKristina. Job stress and the occupational gradient in coronary heart disease risk in women: The Stockholm female coronary risk study. Soc Sci Med 2000; 51:481-489.

23 Pekkarinen A. Development in professional cleaning work brings challenges to ergonomics. The Ergonomics Open Journal 2009; 2: 40-46.

24 Kumar R, Chaikumarn M, et al. Participatory ergonomics and an evaluation of a low-cost improvement effect on cleaners' working posture. Int J Occup Saf Ergon 2005; 11(2): 203210.

25 Kogi K, Kawakami T, et al. Low-cost work improvements that can reduce the risk of musculoskeletal disorders. Int J Ind Ergon 2003; 31(3): 179-184.

26 Martucci WC, Lu Z. A guide to state rest-break legislation for the national employer. Employment Relations Today 2007; 33:67-76.

27 Health and Safety Executive (HSE). Safe use of cleaning chemicals in hospitality. http://www.hse.gov.uk/pubns/cais22.pdf (accessed 6 June 2012).

28 Occupational Safety and Health Administration (OSHA). Workplace violence. http://www.osha.gov/SLTC/workplaceviolence/ (accessed 6 June 2012). 